\title{
Practice among Healthcare Workers Regarding the Use of Respiratory Protective Equipment during COVID-19 Pandemic in a Tertiary Care Center: A Descriptive Cross-sectional Study
}

Sani Sipai, ${ }^{1}$ Bishnu Rath Giri, ${ }^{1}$ Sudhir Sapkota, ${ }^{1}$ Ram Hari Chapagain, ' Santosh Manandhar, ${ }^{1}$ Sudip Chandra Subedi, ${ }^{1}$ Binod Dahal'

'Department of Pediatrics, National Academy of Medical Sciences, Kanti Children's Hospital, Maharajguni, Kathmandu, Nepal.

\section{ABSTRACT}

Introduction: Healthcare workers are always at the risk of exposure to different diseases like respiratory illness including COVID-19. Using appropriate face mask or respiratory protective equipment correctly can prevent transmission of diseases from and to healthcare workers while caring for patients. The study aimed to find out the practice regarding use of face masks during the COVID-19 pandemic in a tertiary care center.

Methods: A descriptive cross-sectional study was conducted at a tertiary care hospital during JuneJuly 2020 after receiving ethical approval from the review committee regarding practice of use of face masks. Convenience sampling method was used and a sample size of 162 was taken. Descriptive statistical analysis was done. Point estimate at 95\% Confidence Interval was calculated along with frequency and proportion for binary data.

Results: Among 162 participants, 123 (75.9\%) knew the correct way of using the masks (72.5-79.3 at 95\% Confidence Interval).

Conclusions: In this study regarding practice of use of face masks, most of the healthcare workers knew the correct way of using masks and practised hygiene before and after using masks.

Keywords: face masks; healthcare workers; practice; respiratory protective equipment.

\section{INTRODUCTION}

Healthcare workers (HCWs) are at high risk of various respiratory hazards including coronavirus disease-19 (COVID-19). World Health Organization (WHO) recommends use of medical mask for all HCWs working in an area with community transmission of COVID-19 and respirators for those working in aerosolgenerating procedures. ${ }^{1}$ Center for Disease Control (CDC) recommends $\mathrm{N} 95$ (or equivalent respirators) or surgical masks to prevent infection to and from HCWs while taking care of patients with suspected or proven disease. All HCWs need to be trained for appropriate use of Respiratory Protection Equipment (RPE). ${ }^{2,3}$

There are few studies about the practice of HCWs regarding the use of RPE especially from developing countries. These studies highlight the deficient supply and improper use of RPE. ${ }^{4-6}$ The search of literatures doesn't reveal any such study from Nepal.

Hence, the study aimed to know the practice regarding use of face masks during the COVID-19 pandemic in a tertiary care hospital of Nepal.

\section{METHODS}

This was a descriptive cross-sectional study conducted among the healthcare workers including doctors, nurses, paramedical staff and laboratory and medical technicians at Kanti Children's Hospital ( $\mathrm{KCH})$, a tertiary care children's hospital in Kathmandu, in June-July

Correspondence: Dr. Sani Sipai, Department of Pediatrics, Kanti Children's Hospital, Kanti Marg, Maharajguni, Kathmandu, Nepal. Email: sanilsonic@gmail.com, Phone: +977-9841498763. 
2020. During the study period, due to the increasing number of COVID-19 cases in the country, there was a lockdown imposed by the government and HCWs were advised to manage duty alternately to minimize exposure in the latter half of the study period when the lockdown was partially relieved. However, the daily new diagnosis of COVID-19 was on the rise and there was no rampant community transmission. There were few kinds of literature and diagnostic facilities available. Ethical approval for this study was obtained from the institutional review committee at $\mathrm{KCH}$ (Ref. no. 842) and informed written consent was taken. All healthcare workers (HCWs) working at the study site, who consented to participate, were included in the study. Healthcare workers working part-time or visiting from other institutes for practices or observership were excluded A convenient sampling method was used and a sample size of 109 was calculated, considering the margin of error at $6 \%$ and confidence interval of $95 \%$, and $88.5 \%$ as the correct knowledge and practice of using face masks in the previous study. ${ }^{6}$

The sample size was calculated using the formula:

$\mathrm{n}=\mathrm{Z}^{2} \times \mathrm{p} \times \mathrm{q} / \mathrm{e}^{2}$

$=(1.96)^{2} \times 0.885 \times 0.115 /(0.06)^{2}$

$=109$

where,

$\mathrm{n}=$ sample size

$\mathrm{Z}=1.96$ at $95 \%$ Confidence Interval $(\mathrm{Cl})$

$\mathrm{p}=$ prevalence of previous study, $88.5 \%{ }^{6}$

$q=1-p=1-0.885=0.115$

$\mathrm{e}=$ margin of error, $6 \%$

Taking $10 \%$ non-response rate, the total sample size becomes 120. However, the total sample taken was 162. The study was conducted by interview using a structured questionnaire. The questionnaire was developed after a review of previous literature on the proper use of surgical face masks and the guidelines of the CDC. ${ }^{2,6,7}$ The questionnaire included basic demographic characteristics (age, gender, job designation), and knowledge, and practice related questions regarding the use of a face mask to limit COVID-19 exposure. During sample collection, some participants did not respond to some of the questions leading to missing data so a valid percentage was considered while finding out results. The information obtained from the participants was entered and calculated using Statistical Package for the Social Sciences (SPSS) Statistics for Windows, Version 20.0. Mean with standard deviations were calculated for age and frequency with percentages for responses with categorical variables.

\section{RESULTS}

A total of 162 participants were included in the study. One hundred twenty-three (75.9\%) (72.5-79.3 at $95 \%$ Confidence Interval) knew the correct way of wearing a surgical mask. On the question about areas required to be covered by surgical masks, 151 (93.2\%) answered correctly (nose, mouth and chin). One hundred fifty eight $(97.5 \%)$ HCWs had the practice of putting on masks while going out and had a practice of wearing masks on hospital premises as well. About 156 (96.3\%) practised hand hygiene before and after using face masks. One hundred twenty-five (77.2\%) of participants reused the face masks.

The mean age of participants was $32.78 \pm 8.55$ years. Among the participants $66(40.7 \%)$ were doctors, 72 $(44.4 \%)$ were nurses, 7 (4.3\%) were laboratory staff, 2 $(1.2 \%)$ were physiotherapists and $6(3.7 \%)$ were others. The median work experience of the participants was 60.0 months. Among them 106 (65.4\%) participants were directly involved in the care of suspected or proven COVID-19 cases.

Fifty-two (32.1\%) responded eight hours as the maximum duration for wearing a face mask with no compromise in safety. About 147 (90.7\%) of participants believed face masks can prevent transmission of respiratory disease like COVID-19. About 58 (35.8\%) of participants believed that both surgical and N95 masks or equivalents are equally effective in preventing respiratory illness like COVID-19.

Out of 162 respondents, 125 (77.2\%) of participants used one mask for the whole day, either new or reused one. About 126 (77.8\%) used surgical masks while $36(22.2 \%)$ used N95 or equivalent masks but no participants used fabric masks. Five $(3.1 \%)$ of them used to remove the mask but 155 (95.7\%) didn't while talking to patients and visitors. About 84 (51.9\%) touched face masks/RPE 1-5 times while 35 (21.6\%) touched 5-10 times and $29(17.9 \%)$ touched more than 10 times in a shift but $13(8.0 \%)$ didn't touch their RPE in a shift. Seventy-four (45.7\%) took off face masks/ RPE 1-2 times while 55 (34.0\%) took off 3-5 times and $14(8.6 \%)$ took off more than 5 times in a shift but only $12(7.4 \%)$ didn't take off their RPE in a shift.

Meanwhile, 117 (72.2\%) of participants stored RPE before reuse. About 45 (27.8\%) stored N95 masks, $27(16.7 \%)$ stored surgical masks while 75 (46.3\%) stored both masks but 13 (8.0\%) didn't store. Fifty-four $(33.3 \%)$ stored surgical masks and 67 (41.4\%) stored N95 masks for 2-3 days before reuse.

Ninety-four (58.0\%) reused surgical masks consecutively for $1-3$ days, 20 (12.3\%) for 3-7 days and $46(28.4 \%)$ did not use a single mask consecutively for more than one day. While 51 (31.5\%) reuse $\mathrm{N} 95$ masks consecutively for $1-3$ days, 70 (43.2\%) for $3-7$ days and 
Sipai et al. Practice among Healthcare Workers Regarding the Use of Respiratory Protective Equipment during COVID-19 Pandemic...

$10(6.2 \%)$ did not use the mask consecutively for more than one day.

For disinfection of mask, $58(35.8 \%)$ of them used sunlight exposure, $38(23.5 \%)$ stored, $26(16.0 \%)$ washed face masks but $18(11.1 \%)$ did not practise disinfection. About 150 (92.6\%) of participants removed face masks from behind the ear or head. During disposal of used face masks, 92 (56.8\%) used a closed lid bin while 67 $(41.4 \%)$ used an open dustbin and $2(1.2 \%)$ disposed of open (Table 1).

\begin{tabular}{|c|c|c|}
\hline Statement & Response & n (\%) \\
\hline Do you practice & Yes & $125(77.2)$ \\
\hline \multicolumn{3}{|l|}{ Reusing face masks? } \\
\hline \multirow{3}{*}{$\begin{array}{l}\text { Average no. of days a } \\
\text { surgical mask reused } \\
\text { consecutively }\end{array}$} & 1 day & $46(28.4)$ \\
\hline & 1-3 days & $94(58.0)$ \\
\hline & 3-7 days & $20(12.3)$ \\
\hline \multirow{4}{*}{$\begin{array}{l}\text { Average no. of days } \\
\text { a N95 mask reused } \\
\text { consecutively }\end{array}$} & 1 day & $10(6.2)$ \\
\hline & $1-3$ days & $51(31.5)$ \\
\hline & 3-7 days & $70(43.2)$ \\
\hline & >7 days & $27(16.7)$ \\
\hline \multirow{2}{*}{$\begin{array}{l}\text { Do you practice } \\
\text { storing face masks } \\
\text { before reuse? }\end{array}$} & Yes & $117(72.2)$ \\
\hline & No & $41(25.3)$ \\
\hline \multirow[t]{4}{*}{$\begin{array}{l}\text { Which type of face } \\
\text { masks do you store? }\end{array}$} & $\begin{array}{l}\text { N95 or } \\
\text { equivalents }\end{array}$ & $45(27.8)$ \\
\hline & Surgical mask & $27(16.7)$ \\
\hline & Both & $75(46.3)$ \\
\hline & I don't store & $13(8.0)$ \\
\hline \multirow{4}{*}{$\begin{array}{l}\text { Average no. of days } \\
\text { a surgical mask is } \\
\text { stored before reuse }\end{array}$} & 1 day & $52(32.1)$ \\
\hline & $2-3$ days & $54(33.3)$ \\
\hline & 3-5 days & $29(17.9)$ \\
\hline & $>5$ days & $22(13.6)$ \\
\hline \multirow{4}{*}{$\begin{array}{l}\text { Average no. of days } \\
\text { a N95 mask is stored } \\
\text { before reuse }\end{array}$} & 1 day & $24(14.8)$ \\
\hline & 2-3 days & $67(41.4)$ \\
\hline & $3-5$ days & $38(23.5)$ \\
\hline & $>5$ days & $28(17.3)$ \\
\hline \multirow[t]{4}{*}{$\begin{array}{l}\text { Response regarding } \\
\text { reusing face masks }\end{array}$} & $\begin{array}{l}\text { Inadequate } \\
\text { supply }\end{array}$ & $141(87.0)$ \\
\hline & It is safe to reuse & $9(5.6)$ \\
\hline & $\begin{array}{l}\text { Disinfection is } \\
\text { quite effective }\end{array}$ & $4(2.5)$ \\
\hline & Others & $6(3.7)$ \\
\hline
\end{tabular}

\begin{tabular}{|lll|}
$\begin{array}{l}\text { What is your practice } \\
\text { of RPE disinfection? }\end{array}$ & None & $18(11.1)$ \\
& Storage & $38(23.5)$ \\
& Sunlight & $58(35.8)$ \\
\hline & Washing & $26(16.0)$ \\
& Spraying spirit & $1(0.6)$ \\
& Others & $19(11.7)$ \\
How do you dispose & In a dustbin & $67(41.4)$ \\
of used RPE? & & \\
& In a closed lid bin & $92(56.8)$ \\
& Open disposal & $2(1.2)$ \\
& I don't know & $1(0.6)$ \\
\hline & &
\end{tabular}

\section{DISCUSSION}

From developing countries, very few studies on the subject have been published. ${ }^{3-6}$ This study aimed to know the practice of HCWs on the use of RPE. The results indicated that most of the studied HCWs had good practice regarding the use of RPE. All the participants who responded had the practice of putting on masks while going out and in hospital premises. This study showed $75.9 \%$ of the participants knew the correct way of wearing a surgical mask and $93.2 \% \mathrm{knew}$ about areas required to be covered by surgical masks. As compared to the study in Pakistan by Kumar J, and et al. ${ }^{6}$ showed, $88.5 \%$ of participants knew the proper steps of wearing a surgical face mask. The correct way of wearing a surgical mask is by facing out the coloured side independent of health status. ${ }^{8}$

In the study by Wada $\mathrm{K}$ and et al. ${ }^{9}$ participants wearing a face mask were reported to be practising additional preventive hygiene measures while in this study, $96.3 \%$ practised hand hygiene before and after using face masks.

This study found that only $3.1 \%$ of them used to remove the mask while talking to patients and visitors, but $51.9 \%$ touched face masks/RPE $1-5$ times in a shift and $45.7 \%$ took off face masks/RPE 1-2 times in a shift while in the study by Kumar $\mathrm{J}$ et al. ${ }^{6}$ found $13.8 \%$ of them removed the mask to talk with patients.

The proportion of reuse is very high. We found $77.2 \%$ of participants reused the RPE (face masks) and $72.2 \%$ stored RPE before reuse; $27.8 \%$ stored N95 masks, $16.7 \%$ stored surgical masks and $46.3 \%$ stored both masks. ${ }^{10}$ As compared to study by Kumar $\mathrm{J}$ et al..$^{6}$ found only $20.2 \%$ reused face masks. Although statistically not significant, $69.7 \%$ of doctors as compared to $83.2 \%$ of other staff reused face masks. The reason for more than $85 \%$ reuse is decreased supply. ${ }^{11}$

Consecutive use is not safe but $58 \%$ of our HCWs are practicing consecutive use. People tend to use N95 or equivalents for more days consecutively than surgical 
masks.

A colour-coded bin system is recommended for the proper disposal of biomedical waste in hospitals. ${ }^{12}$ Kumar $\mathrm{J}$ et al. ${ }^{6}$ found $44.9 \%$ disposed of in the yellowcoded bag for disposal of face mask; while our study found that $56.8 \%$ used closed lid bins for disposal.

The limitations of this study include the cross-sectional nature of the study design limited to one hospital with a small sample size. Further studies should be carried out on a larger sample size so that the results could be generalized.

\section{CONCLUSIONS}

The practice of the use of respiratory protective equipment or face masks among the healthcare workers at a tertiary care children's hospital was found that HCWs knew the correct way of using masks and areas to be covered by masks. HCWs practised hygiene before and after using face masks. However, due to inadequate supply, they were reusing the face masks. All the participants who responded had the practice of putting on masks while going out and when on hospital premises. It was found that very few participants used to remove the mask while talking to patients and visitors, but around half of them touched face masks/RPE 1-5 times and took off face masks/RPE 1-2 times in a shift. More than half of the participants used a closed lid bin during the disposal of used face masks. More studies of similar nature are urgently required from different countries.

\section{Conflict of Interest: None.}

\section{REFERENCES}

1. WHO. Advice on the use of masks in the context of COVID-19: Interim guidance [Internet]. Geneva: World Health Organization; 2020 Jun 5 [cited 2021 Apr 24]. Available from: https://apps.who.int/iris/rest/bitstreams/1274340/ retrieve. [Full Text]

2. CDC. Interim infection prevention and control recommendations for healthcare personnel during the Coronavirus Disease 2019 (COVID-19) Pandemic [Internet]. Atlanta (US): Centers for Disease Control and Prevention; 2020 [cited 2020 Jun 6]. Available from: https://www.cdc. gov/coronavirus/2019-ncov/hcp/infection-control-recommendations.html. [Full Text]

3. Honarbakhsh $\mathrm{M}$, Jahangiri $\mathrm{M}$, Ghaem H. Knowledge, perceptions and practices of healthcare workers regarding the use of respiratory protection equipment at Iran hospitals. J Infect Prev. 2017 Sep 6 [cited 2020 Jul 11]. [PubMed | Full Text| DOI]

4. Chughtai AA, Seale H, Chi Dung T, Maher L, Nga PT, MacIntyre CR. Current practices and barriers to the use of facemasks and respirators among hospital-based health care workers in Vietnam. Am J Infect Control. 2015 Jan; 43(1):72-7. [PubMed | Full Text | DOI]

5. Seale H, Macintyre C, Mclaws M, Maher L, Newall A, Kaur $\mathrm{R}$, et al. Health care worker practices around face mask use in hospitals in Hanoi, Vietnam. Int J Infect Dis. 2012 Jun 1; 16:e384. [Full Text | DOI]

6. Kumar J, Katto MS, Siddiqui AA, Sahito B, Jamil M, Rasheed $\mathrm{N}$, et al. Knowledge, Attitude, and Practices of Healthcare Workers Regarding the Use of Face Mask to Limit the Spread of the New Coronavirus Disease (COVID-19). Cureus.

\section{0;12(4). [PubMed | Full Text | DOI]}

7. Ho HSW. Use of face masks in a primary care outpatient setting in Hong Kong: knowledge, attitudes and practices. Public Health. 2012; 126(12):1001-6. [uuMed | Full Text $\mid$ DOI]

8. WHO. When and how to use masks [Internet]. [cited 2020 Sep 15]. Available from: https://www.who.int/emergencies/ diseases/novel-coronavirus-2019/advice-for-public/ when-and-how-to-use-masks. [Full Text]

9. Wada K, Oka-Ezoe K, Smith DR. Wearing face masks in public during the influenza season may reflect other positive hygiene practices in Japan. BMC Public Health [Internet]. 2012 Dec 10 [cited 2020 Jul 11];12(1):1065. [PubMed | Full Text | DOI]

10. Mackenzie D. Reuse of N95 Masks. Eng Beijing China [Internet]. 2020 Jun [cited 2020 Jul 11];6(6):593-6. [PubMed | Full Text | DOI]

11. Chughtai AA, Stelzer-Braid S, Rawlinson W, Pontivivo G, Wang $Q$, Pan $Y$, et al. Contamination by respiratory viruses on outer surface of medical masks used by hospital healthcare workers. BMC Infect Dis [Internet]. 2019 Jun 3 [cited 2020 Jul 11];19(1):491. [PubMed | Full Text | DOI]

12. Chartier Y, Emmanuel J, Pieper U, Prüss A, Rushbrook $\mathrm{P}$, Stringer R, et al.(ed). Safe Management of Wastes from Health-Care Activities. World Health Organization, Geneva

The Author(s) 2018

This work is licensed under a Creative Commons Attribution 4.0 International License. The images or other third party material in this article are included in the article's Creative Commons license, unless indicated otherwise in the credit line; if the material is not included under the Creative Commons license, users will need to obtain permission from the license holder to reproduce the material. To view a copy of this license, visit http://creativecommons.org/licenses/by/4.0/ 